\title{
An overview of the anti-cancer actions of Tanshinones, derived from Salvia miltiorrhiza (Danshen)
}

Irum $\mathrm{Naz}^{1}$, Myriam Merarchi², Shanaya Ramchandani ${ }^{3}$, Muhammad Rashid Khan ${ }^{*}$, Muhammad Nouman Malik $^{1}$, Sumaira Sarwar ${ }^{1}$, Acharan S Narula ${ }^{5}$, Kwang Seok Ahn ${ }^{6^{*}}$

${ }^{1}$ Department of Biochemistry, Faculty of Biological Sciences, Quaid-i-Azam University, Islamabad 45320, Pakistan

${ }^{2}$ Faculty of Pharmacy, University of Paris Descartes, 75006 Paris, France

${ }^{3}$ Department of Pharmacology-Biomedicine, The University of Melbourne, Parkville, VIC 3010, Australia

${ }^{4}$ Higher Education Commission of Pakistan, Islamabad 44000, Pakistan

${ }^{5}$ Narula Research, Chapel Hill, NC 27516, USA

${ }^{6}$ Department of Science in Korean Medicine, College of Korean Medicine, Kyung Hee University, 24 Kyungheedae-ro, Dongdaemun-gu, Seoul 02447, South Korea

*Correspondence: Muhammad Rashid Khan, Department of Biochemistry, Faculty of Biological Sciences, Quaid-i-Azam University, Islamabad 45320, Pakistan. mrkhanqau@yahoo.com; Kwang Seok Ahn, Department of Science in Korean Medicine, College of Korean Medicine, Kyung Hee University, 24 Kyungheedae-ro, Dongdaemun-gu, Seoul 02447, South Korea. ksahn@ khu.ac.kr

Academic Editor: Gautam Sethi, National University of Singapore, Singapore

Received: April 16, 2020 Accepted: May 17, 2020 Published: June 29, 2020

Cite this article: Naz I, Merarchi M, Ramchandani S, Khan MR, Malik MN, Sarwar S, et al. An overview of the anti-cancer actions of Tanshinones, derived from Salvia miltiorrhiza (Danshen). Explor Target Antitumor Ther. 2020;1:153-70. https://doi. org/10.37349/etat.2020.00010

\begin{abstract}
Tanshinone is a herbal medicinal compound described in Chinese medicine, extracted from the roots of Salvia miltiorrhiza (Danshen). This family of compounds, including Tanshinone IIA and Tanshinone I, have shown remarkable potential as anti-cancer molecules, especially against breast, cervical, colorectal, gastric, lung, and prostate cancer cell lines, as well as leukaemia, melanoma, and hepatocellular carcinoma among others. Recent data has indicated that Tanshinones can modulate multiple molecular pathways such as PI3K/Akt, MAPK and JAK/STAT3, and exert their pharmacological effects against different malignancies. In addition, preclinical and clinical data, together with the safety profile of Tanshinones, encourage further applications of these compounds in cancer therapeutics. In this review article, the effect of Tanshinones on different cancers, challenges in their pharmacological development, and opportunities to harness their clinical potential have been documented.
\end{abstract}

\section{Keywords}

Tanshinone, cancer, signalling pathways, apoptosis, angiogenesis, pharmacokinetics 


\section{Introduction}

Cancer is the second leading cause of death worldwide and causes a significant loss of human life. In recent years, the incidence and mortality rates of cancer have shown rapid growth, thus, becoming a major public health challenge. According to a recent report published by the World Health Organisation, cancer is the cause of $70 \%$ of deaths in low and medium-income countries [1]. Currently, antineoplastic drugs being used for the treatment of cancer can be divided into two categories: targeted and non-targeted drugs. Nontargeted drugs such as Adriamycin, Cisplatin, and Paclitaxel can effectively inhibit tumor progression but have shown severe side effects on human normal cells [2]. Targeted drugs are available in the market that can affect specific oncogenic signalling pathways; however, high cost makes these drugs unaffordable in many developing countries. Hence, the discovery of low-cost targeted drugs has become an urgent need for cancer therapy. For millennia, natural products, including those derived from plants, animals, and microorganisms, have been extracted and synthesized [3,4]. These products can provide prototypes for the synthesis of pharmacologically active agents, specifically, antineoplastic agents [5-9] and have been found to be effective against different cancers [10-13]. This review analyzes the significance of Tanshinones in cancer prevention as well as treatment in different tumor models.

Tanshinone (Tan) is a herbal medicinal compound reported in Chinese medicine. More than forty Tan compounds have been extracted from Salvia miltiorrhiza (Danshen), although some compounds have also been derived from other plant species including S. argentea, S. aerea, S. kiaometiensis, S. vasta, and S. yunnanensis [14]. Interestingly, Tan compounds identified in Salvia miltiorrhiza roots (Formula: $\mathrm{C}_{19} \mathrm{H}_{18} \mathrm{O}_{3}$ ) are liposoluble naphthoquinone diterpenes and have been reported to exhibit great potential against cardiovascular diseases and for stroke treatment. Tanshinones, including Tanshinone I (Tan I) and Tanshinone IIA (Tan IIA) can suppress the growth of multiple cancers including those of bladder [15], breast [16-18], cervical [19], liver [20,21], lung [2-31], pancreatic and prostate cancer (PC) [32-36]. In addition, these bioactive compounds can modulate the growth of astrocytoma [37], endometrial carcinoma [38], mesothelioma [39], melanoma, and leukaemia [40, 41] as well as osteosarcoma [42] and ovarian carcinoma [43-45].

Tan I compound $\left(\mathrm{C}_{19} \mathrm{H}_{18} \mathrm{O}_{3}\right)$ has a molecular weight of $276.3 \mathrm{~g} / \mathrm{mol}$ (Figure 1a), and has been identified from Salvia species. Tan I can display extensive anticoagulant, immunosuppressive, antineoplastic, phytogenic, anti-inflammatory, and anti-infective properties. Among Tanshinones, Tan IIA (molecular weight of $294.3 \mathrm{~g} / \mathrm{mol}$ ) is the most abundant compound from the Salvia species and its structure has been shown in Figure 1b. Interestingly, Tan IIA, in addition to its promising antineoplastic effects, can also exhibit antiinflammatory, non-steroidal, and anti-infective properties. In general, Tanshinones have poor bioavailability and can be more effective when injected intravenously. This article aims to provide an updated review of Tan compounds and their modes of actions against different malignancies.
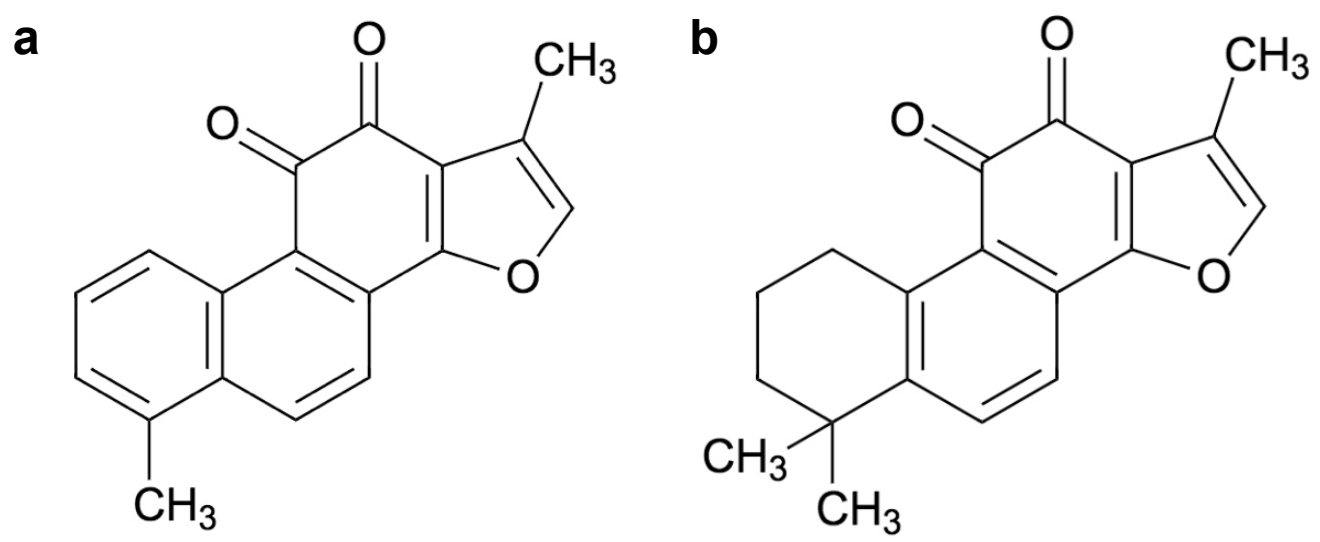

Figure 1. Molecular structure of Tanshinones: (a) Tan I and (b) Tan IIA

\section{Molecular pathways affected by Tan}

The various Tan compounds have the ability to target multiple oncogenic signalling pathways and abrogate malignant transformation. Numerous studies have been conducted on Tan IIA and Tan I compounds to 
determine their effect on various pathways that can promote tumorigenesis and these are discussed briefly below.

\section{Tan IIA}

The generation of reactive oxygen species (ROS) inside mitochondria can promote oxidative stress which can regulate the activation of apoptotic signalling pathways [46-49]. Upon treatment with Tan IIA, the level of ROS was elevated, resulting in inductionof apoptosis through the modulation of phosphoinositide 3-kinase (PI3K), AKT, m-TOR, and c-Jun N-terminal kinase (JNK) pathways [43, 50, 51]. Tan IIA has been found to suppress the adenosine monophosphate-activated protein kinase (AMPK) pathway resulting in the inactivation of Sphase kinase associated protein 2 (Skp2), which can promote mitochondrial apoptosis via inhibition of mitophagy [52]. Human papillomavirus (HPV), a well-known causative agent of cervical cancer, encodes the E6 and E7 viral oncoprotein, which can result in the inactivation of tumor suppressor proteins p53 and retinoblastoma protein (pRB). In HPV positive human cervical cancer CaSki cells, Tan IIA displayed multiple pharmacological effects and reduced the expression of E6 and E7 and eventually altered the levels of proteins such as E6AP, E2F1, and pRb. It also triggered p53 accumulation, altered p53-dependent expression of target genes, and mediated p53 dependent apoptosis through modulation of B-cell lymphoma-2 (Bcl-2), caspase-3, and poly ADP-ribose polymerase (PARP) expression [19]. Interestingly, Tan IIA also caused both

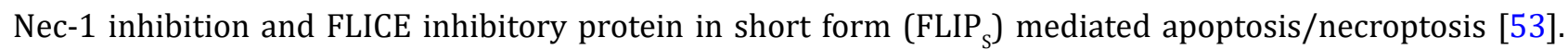
Moreover, Tan IIA can affect multiple transcription factors and modulate the levels of phosphorylated p65, and in turn, suppressed the activation of nuclear factor kappa light chain enhancer of activated B cells (NFкB) signalling pathway and also abrogate JAK/STAT3 signalling pathway [54, 55]. Through these molecular mechanisms, Tan IIA may have the ability to target specific proteins in human cancer cells. The multiple molecular mechanisms of action of Tan IIA have been summarized below (Figure 2).

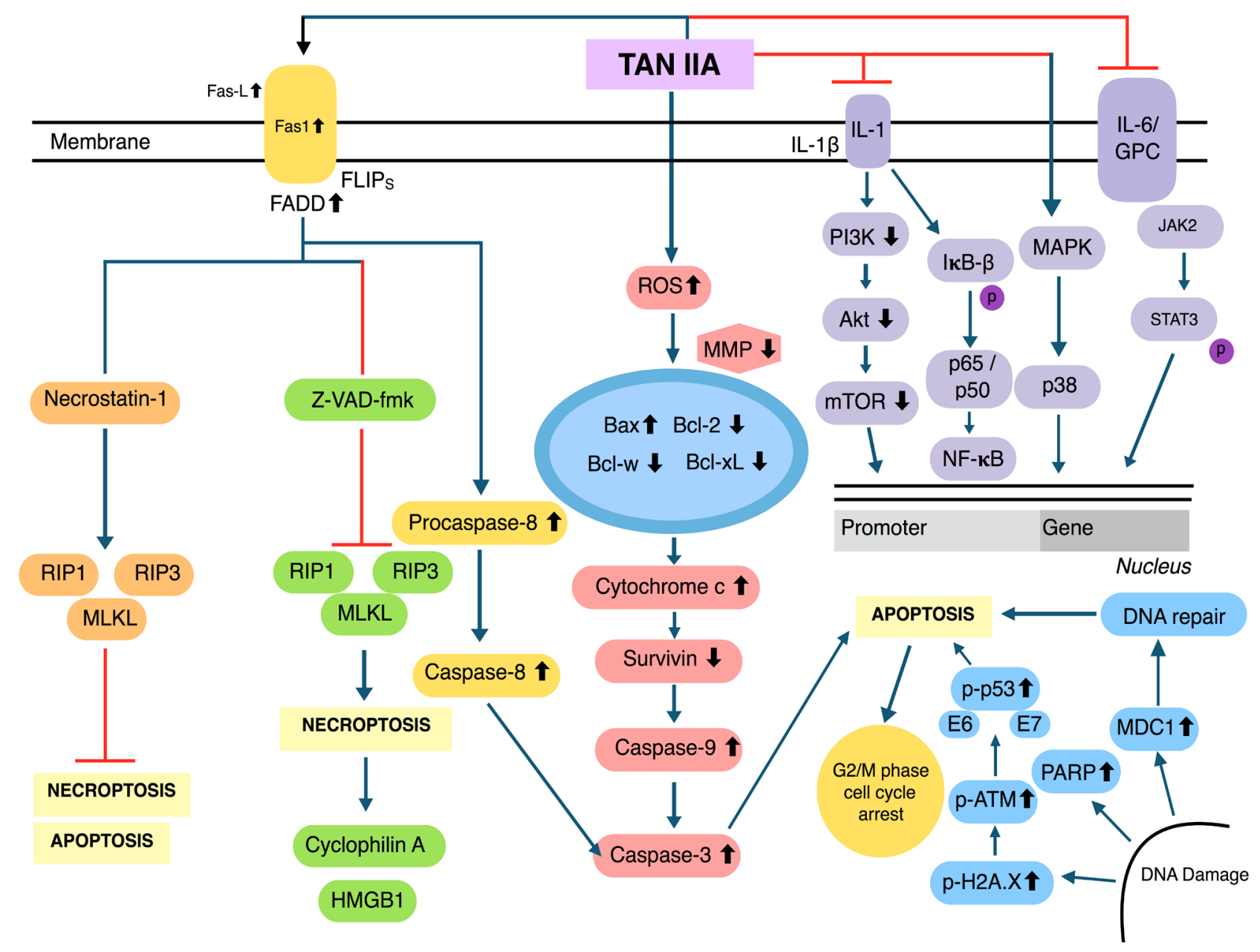

Figure 2. Multiple molecular signalling pathways of Tan IIA. MMP: matrix metalloproteinase; HMGB1: high-mobility group protein B1 


\section{Tan I}

Pre-treatment with Tan I on various malignancies induced apoptosis through an increased ROS production and substantially reduced the MMPs level [38]. Additional studies have indicated that Tan I can induce apoptosis and autophagy through the aggregation of p62 (C-terminal UBA domain being required for this aggregation), as well as by causing an up-regulation of inositol-requiring protein-1 (IRE1), CCAAT-enhancerbinding protein homologous protein (CHOP), and p-c-Jun N-terminal kinase (p-JNK) [39]. In addition, Tan I was found to reduce Bcl-2 protein expression, as well as increase the conversion of LC3I to LC3II and trigger autophagosome formation without altering the expression of Beclin-1. This could increase Beclin1VPS $_{34}$ complexes and thus induce both apoptosis as well as autophagy [56]. Lu et al. [57], documented that Tan I affected Aurora A-p53 and survivin-induced signalling pathways and caused an upregulation of PARP levels, which enhanced p-p53 protein expression and reduced the levels of Aurora A kinase. This action, as well as the modulation of caspase- 3 and caspase- 9 led to an induction of apoptosis in colorectal cancer (CRC) cells. In addition, Tan I cleaved procaspase-8, which attenuated the expression of Bid and t-Bid, thereby in turn activating caspase-2. In contrast, Tan IIA has been shown to modulate vascular epidermal growth factor receptor (VEGFR) as well as Ras/Raf/MEK/ERK pathway in AGS gastric carcinoma cells [58]. Moreover, Tan I downregulated the activation of the PI3K/Akt/m-TOR pathway leading to a substantial level of apoptosis in breast cancer cells [17]. The molecular mechanisms of Tan I have been briefly depicted in the figure below (Figure 3).

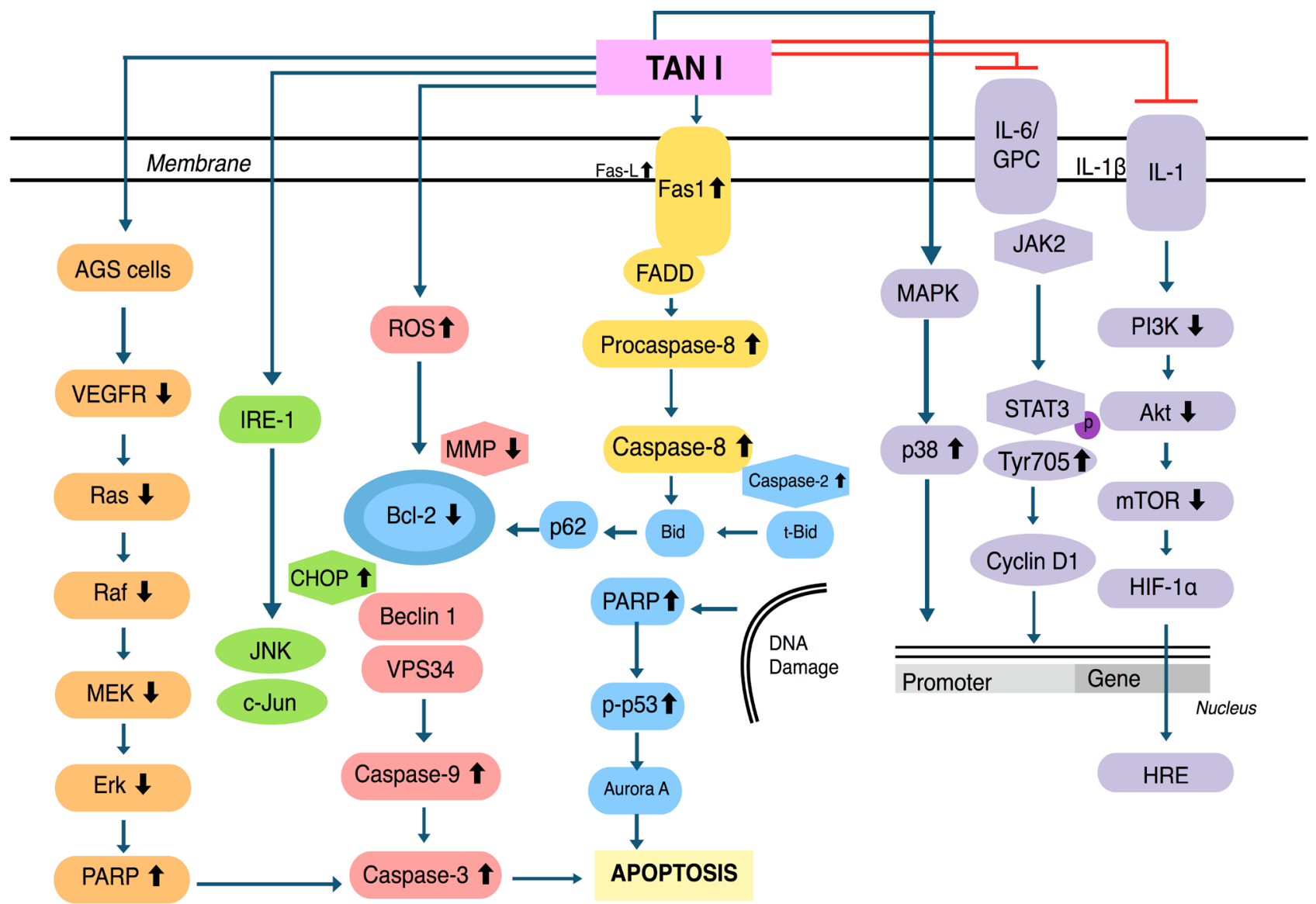

Figure 3. Multiple molecular signalling pathways regulated by Tan I

\section{Anti-cancer effects of Tan}

Despite the use of Tan compounds to treat cardiovascular disease and strokes in Traditional Chinese Medicine, they also have exhibited antineoplastic effects against numerous malignancies. This section of the review will further elaborate on these anti-tumoral effects, including the induction of apoptosis, inhibition of angiogenesis, and metastasis against different tumor cells (Table 1). 
Table 1. Selected anti-cancer effects of Tan compounds in-vitro

\begin{tabular}{|c|c|c|c|}
\hline Cancer type & Cell line & Pathways/molecules altered & References \\
\hline Astrocytoma & Astrocytoma cells & $\uparrow$ Notch-1 & [97] \\
\hline Breast cancer & MDA-MB-231, MCF-7 & $\downarrow$ HIF-1a, $\downarrow$ VEGF & [102] [16] \\
\hline Bladder cancer & $\mathrm{BCa}$ & $\downarrow$ EMT & [15] \\
\hline \multirow[t]{2}{*}{ Cervical cancer } & HPV positive CaSki & $\downarrow$ E6 and E7, $\uparrow$ p53 & [19] \\
\hline & & $\downarrow$ CYP2J2-mediated astemizole O-demethylation & [19] [117] \\
\hline Cervix carcinoma & $\begin{array}{l}\text { Stemness-like cancer } \\
\text { cells }\end{array}$ & $\downarrow$ YAP mRNAs & [98] \\
\hline \multirow[t]{2}{*}{ Colon cancer } & SW480 & $\uparrow$ E-cadherin, $\downarrow$ vimentin and MMP-9 & [118] \\
\hline & CRC & $\downarrow$ AMPK, $\uparrow S k p 2$ & [52] \\
\hline Esophageal cancer & EC-109 & $\uparrow$ caspase- $4, \uparrow \mathrm{CHO}$ & [24] \\
\hline \multirow[t]{2}{*}{ Gastric cancer } & AGS & $\begin{array}{l}\downarrow \text { EGFR, } \downarrow \text { IGFR, } \downarrow \text { PI3K, } \downarrow \text { AKT, } \downarrow \text { mTOR, } \downarrow \text { NF-KB-p65, } \downarrow \text { COX- } \\
2 \text { and MMP-2, }-7 \text { and }-9 \mathrm{~S}, \uparrow p-p 38, \uparrow p-J N K, \uparrow p 53, \uparrow p 21, \\
\uparrow \text { caspase-3 and caspase-8, } \uparrow \text { PARP }\end{array}$ & [119] [58] \\
\hline & & $\downarrow$ VEGFR, $\downarrow$ HER2, $\downarrow$ Ras, $\downarrow$ Raf, $\downarrow$ MEK, $\downarrow$ ERK & \\
\hline \multirow[t]{2}{*}{ Gastric cancer } & SGC-7901 & $\downarrow$ Ki-67, $\downarrow$ PCAN,$\downarrow$ MMP-2, $\downarrow$ MMP-9, $\downarrow$ FOXM1,$\uparrow P 21$ & [69] \\
\hline & SNU-638 \& MKN1 & $\uparrow$ Bcl-2, $\downarrow$ caspase-3, $\downarrow$ p-STAT3 & [54] [37] \\
\hline Glioma & U251 & $\downarrow \mathrm{p}$-PI3K, $\downarrow$ Bcl-2, $\downarrow$ p-Akt, $\uparrow$ Bax, $\uparrow$ LC3B, $\uparrow$ Beclin 1 & [37] \\
\hline Leukaemia & APL & $\mathrm{C} / \mathrm{EBP} \beta$ & [99] \\
\hline \multirow[t]{2}{*}{ Liver cancer } & HepG2 & $\downarrow$ CYP2J2 activity & [117] \\
\hline & HepG2 & $\uparrow L D L R, \uparrow p 53, \downarrow$ HNF-1a, $\downarrow$ Nec- $1, \downarrow$ PCSK9 & [53] [81] \\
\hline Lung cancer & A549 & $\begin{array}{l}\uparrow \text { Cleaved Caspase-3 and Bax, } \downarrow \text { VEGF, } \downarrow \text { VEGFR2, } \downarrow p-P I 3 K \\
\downarrow p \text {-Akt, } \downarrow \text { Bcl- } 2, \downarrow \text { Caspase-3 protein }\end{array}$ & $\begin{array}{l}{[25][26][30]} \\
{[31]}\end{array}$ \\
\hline Melanoma & A375 & $\begin{array}{l}\uparrow \text { Beclin-1, } \uparrow \text { LC3-II expression, } \downarrow \text { pPI3K, } \downarrow p-A K T, \downarrow p-m T O R, \\
\downarrow p-p 7036 k 1\end{array}$ & [41] \\
\hline Oral cancer & $\begin{array}{l}\text { SCC-9 squamous } \\
\text { carcinoma }\end{array}$ & $\uparrow R O S, \uparrow B e c l i n$ 1, $\uparrow$ Atg5 & [89] [90] \\
\hline Ovarian cancer & TOV-21G & $\begin{array}{l}\uparrow \text { TRAIL-induced apoptosis, } \uparrow \text { DR5, } \uparrow \text { ROS-JNK-CHOP, } \uparrow \text { miR-205, } \\
\uparrow B c l-2 \downarrow \text { Mcl-1L, } \downarrow \text { PI3K, } \downarrow \text { AKT, } \downarrow \text { JNK }\end{array}$ & [43] [45] \\
\hline \multirow[t]{2}{*}{ Osteosarcoma } & $143 B$ & $\downarrow$ Ki67, $\downarrow$ PCNA & [42] \\
\hline & MG-63 & $\uparrow$ Cleaved-PARP, $\uparrow$ ROS, $\uparrow$ Caspase- $3,-8$ and -9 & [96] \\
\hline \multirow[t]{3}{*}{ PC } & PC-3 & $\downarrow$ Beclin1, $\downarrow$ LC3-II & [32] \\
\hline & LNCaP & $\uparrow$ maspin, $\uparrow A R s$ & [120] \\
\hline & $\mathrm{PC} 12$ & $\downarrow p$-Akt, $\downarrow p$-ERK1/2, $\uparrow p-F O X O 3 a, \uparrow c-R a f$ & [121] \\
\hline
\end{tabular}

EMT: epithelial-mesenchymal transition; FoxM1: forkhead box M1; MMP-2: matrix metalloproteinase 2; MMP-9: matrix metalloproteinase 9

\section{Effect of Tanshinones against different cancers}

\section{Tan and breast cancer}

According to the World Health Organisation, breast cancer is the second-most commonly occurring cancer worldwide, following lung cancer [59-62]. Like many other cancers, chemoresistance remains a notable issue when using Taxol; a well-known chemotherapeutic agent used in breast cancer patients. Tan IIA in combination with Taxol was found to considerably reduce the resistance of breast cancer MCF-7 (taxol resistant) cells by causing an abrogation of microtubule associated protein [16]. It is interesting to note that both estrogen receptor-responsive MCF-7 and estrogen-independent MDA-MB-453 human breast cancer cells were found responsive to Tan I, irrespective of their sensitivity to estrogen [17]. In addition, Tan I attenuated the levels of HIF- $1 \alpha$ and p-705-STAT3 and the secretion of VEGF in MCF-7 cells [63]. Likewise, an acetyl Tan IIA, a chemically modified Tan IIA derivative can induce apoptosis through increased ROS generation, by increasing the level of pro-apoptotic Bcl-2-associated-X protein (Bax), thereby causing caspase- 3 activation and cytochrome c release in HER2 positive breast cancer cells [18]. 


\section{Tan and cervical cancer}

According to the American Institute of cancer research, cervical cancer is the fourth-deadliest cancer in women and ranks eighth in most commonly occurring cancer worldwide [64]. Cervical cancer interventions mainly focus on primary and secondary prevention strategies. Primary prevention is the best way to diminish the burden of cervical cancer and its related mortality. HPV is recognized as an etiological factor in cervical cancer induction [65]. In HPV, the oncogenes $E 6$ and $E 7$ have been reported to inactivate tumor suppressor proteins p53 and pRb. In HPV positive CaSki cells, it has been shown that Tan IIA can down-regulate the expression of these vital oncogenes by regulating the expression of their associated proteins E6AP, E2F1, pRb that can cause an accumulation of p53 and p53-dependent downstream targets and can also modulate the levels of Bcl-2, Bax, and caspase-3 thereby promoting PARP cleavage [19]. Furthermore, in HPV positive CaSki cells, Tan IIA can induce apoptosis and block the $S$ phase progression of the cell cycle effectively [19].

\section{Tan and colorectal \& gastric cancer}

Following lung and breast cancer, CRC is the third-deadliest cancer, particularly in Western countries, whereas chemoresistance is a major problem in gastric cancer $[1,66]$. It is, therefore, imperative to find suitable treatments for these cancers. In Tan I-treated HCT116 and SW480 human CRC cells, inhibition of cell proliferation along with a decreased level of cyclin D1 protein was observed [67]. In addition, in CRC cells, Tan I induced apoptosis and specifically suppressed CRC cell growth [67]. A study reported by Kim et al. [68], has indicated a significant potential of Tan I in reducing the viability of HCT116 and HT29 cells. On the contrary, Tan IIA was shown to enhance CRC apoptosis through the suppression of the MAPK pathway and the inactivation of Spk2 proteins [52]. A study reported by Jing et al. [56], indicated that Tan I could effectively suppress the proliferation, as well as promote apoptosis in BGC823, and SGC7901 human gastric cancer cells. Likewise, Tan IIA was noted to significantly induce apoptosis, inhibit migration and proliferation in AGS and SGC-7901 gastric cancer cells [58, 69]. Tan IIA effectively suppressed the proliferation of multiple gastric cancer cell lines including SNU-638, MKN1, and AGS, while inducing apoptosis via mediating increased level of cleaved caspase-3 and decreased expression of Bcl-2 [54]. It is important to note that Dihydrotanshinone (DT), another derivative of Tanshinones, displayed significantly higher cytotoxicity when compared with other Tanshinones in SGC7901 and MGC803 gastric cancer cells [70]. However, exposure of Tan IIA on colon cancer cell lines including SW480 and HC8693 reduced cellular growth, and invasive potential [71]. In addition, IL-2-based treatment in combination with Tan IIA enhanced the IL-2-mediated cell death and reduced proliferation of SW480 cells [72]. In another study by using similar SW837 cells, Tan IIA promoted cell death, impaired cell migration, and mediated proliferation arrest [73]. Overall, through these pleiotropic mechanisms, Tan I and Tan IIA compounds may have a substantial ability to inhibit the growth of colorectal and gastric cancers.

\section{Tan and esophageal cancer}

Esophageal cancer is one of the least curable cancers with a survival rate between 5-30\% post five years of diagnosis [74]. Tan IIA can inhibit proliferation via modulating Akt pathway and directly induce cell cycle arrest by sequestering EC109 esophageal cancer cells in S phase [23]. Additionally, Tan IIA could also initiate apoptosis either through activation of $\mathrm{CHOP} /$ caspase pathway by sequentially increasing caspase- 3 and caspase- 9 expression, altering Bax/ Bcl-2 ratio, or modulating endoplasmic reticulum caspase- 4 and CHOP levels in a dose dependent manner [24]. Another study reported that Tan IIA can substantially suppress proliferation through targeting Cyclin B1 protein, which led to an interruption of cell cycle in S and G2/M phases and induced apoptosis in EC-1 and ECa-109 esophageal carcinoma cell lines [28].

\section{Tan and hepatocellular carcinoma (HCC)}

Liver cancer is the fifth most common cause of cancer death worldwide, whereas estimated deaths will rapidly keep on increasing in 2020 and beyond [75-79]. Tan IIA coupled with mPEG-PLGA-PLL-cRGD (methoxy polyethylene glycol, polylactic-co-glycolic acid, poly-L-lysine, and cyclic arginine-glycine-aspartic acid) when used to treat HCC has shown improved anti-tumoral activities [21]. Tan IIA in combination with trans-resveratrol exerted synergistic apoptosis and cytotoxicity comparable to that of cisplatin [20]. In HepG2 
human liver cancer cells, Tan IIA upregulated low-density lipoprotein receptor (LDLR) and altered the levels of PCSK9 protein. Tan IIA also increased forkhead box class 0 3a (FOXO3a) expression, which attenuated levels of PCSK9 protein in HepG2 cells [80]. Tan IIA modified apoptosis to necroptosis through promoting necrostatin-1 inhibition and downregulating FLIP $_{S}$ receptor [53]. A study conducted by Ren et al. [81], stated that Tan IIA can exhibit anti-oncogenic activity through apoptosis induction caused by increased Bax/ Bcl-2 ratio and altered levels of caspase-3, p21, cyclin D1, and cyclin dependent kinase 6 in hepatocellular carcinoma cells. Moreover, Tan IIA treatment upregulated the level of p53 protein as well as PTPN11 and its encoded protein SHP2 that can mediate its possible anticancer activities [81].

\section{Tan and lung cancer}

Lung cancer is the leading cause of cancer-related death worldwide [82-86]. It was reported that Tan IIA suppressed proliferation, angiogenesis, activated apoptosis, and caused cell cycle arrest at the $S$ phase through a decrease in the expression of vascular endothelial growth factor (VEGF) and VEGFR2 proteins in A549, PC9, and HLF lung cancer cells [25]. Additionally, Tan IIA in combination with adriamycin remarkably suppressed migration, activated apoptosis, and arrested cell cycle, particularly in A549 cells [26]. In radioresistant lung cancer H358-IR and H157-IR cells, treatment with Tan I caused an inhibition of cell proliferation, which could lead to an enhancement of radiosensitivity. Tan I was docked into the active site of phosphoribosyl pyrophosphate amidotransferase (PPAT) protein, and was found to attenuate PPAT signalling [29]. Likewise, in lung adenocarcinoma PC9 cells, DT arrested proliferation and activated the apoptotic process. The expression of Bax, IRE-1, Bip, and caspase-12 was augmented upon DT exposure and caused apoptosis [30]. Interestingly, Tanshinones could also attenuate non-small cell lung cancer growth by suppressing AURKA an oncogene via augmenting the expression of miR-32 and other related miRNAs [31], and thus can act as effective therapeutic agents.

\section{Tan and oral cancer}

Treatment for oral cancer thus far has not been quite promising when the tumor is detected at a metastatic stage, with a 5-year survival rate of around 39\% [75, 87, 88]. In human oral squamous cell carcinoma (SCC09), Tan IIA can exhibit radio-sensitizing effects and can induce autophagy. Pre-treatment with Tan increased ROS generation, upregulated Beclin-1, Atg5, and LC3-III proteins [89]. In another study, the administration of Tan in SCC-9 cells increased apoptosis by modulating the PI3K/Akt pathway, increased cleaved-caspase-3 expression, as well as the ratio of LC3-II to LC3-I [90].

\section{Tan and ovarian cancer}

Ovarian cancer is the second most common cause of gynaecological cancer-associated mortality globally [75]. In a study conducted on ovarian cancer cells, Tan IIA caused activation of caspase $-3,-8$, and -9 and decreased the expression of Bcl-2 [43]. In A2780 human ovarian carcinoma cells, it has been demonstrated that Tan IIA can enhance TRAIL-induced apoptosis by up-regulating death receptor 5 (DR5) through the ROS/JNK/ CHOP pathway. Indeed, DR5 was noted to be stimulated via the up-regulation of CCAAT/enhancer-binding protein homologous protein [44]. In ovarian carcinoma Tan IIA-treated TOV-21G cells, apoptosis was induced through the downregulation of survivin, while the levels of Bax, Bcl-2, and B-cell lymphoma-extra-large (Bcl-xL) remained unaffected. It also caused miR-205 overexpression, which altered the levels of survivin protein [45]. Specifically, through the modulation of ROS/JNK/CHOP pathway, Tan IIA can inhibit growth and induce apoptosis in ovarian cancer cell lines.

\section{Tan and PC}

PC is a leading cause of death in men, especially among the aged men [91-94]. Tan IIA-treated human PC-3 cells, displayed mitochondrial-dependent apoptosis and autophagy, that were found to be dependent on ROS production [32-34]. Moreover, PTS33, a new sodium derivative of cryptotanshinone was noted to selectively inhibit androgen receptor (AR) activities, and effectively suppress the growth of AR-positive PC cells, while the effect on AR-negative PC cells was limited [35]. The insulin-like growth factor 1 (IGF-1) and its receptor (IGF-1R) can facilitate tumor proliferation and progression. In another study, PC12 cells were treated with 
IGF-1 with or without Tan IIA, and the results have shown that IGF-1 can promote the growth of PC12 cells and Tan IIA inhibited their growth significantly [36].

\section{Tan and other cancers}

Tan compounds are able to target several other cancer cells, including bladder cancer, pancreatic cancer, osteosarcoma, melanoma, and leukaemia; the specific actions of Tanshinones on various cancers have been elaborated below. In human bladder cancer cell lines, 5637, BFTC and T24, Tan IIA was found to suppress the proliferation, migration, and metastasis [15]. It can abrogate the growth of MiaPaCa-2 pancreatic cancer cells by interrupting the ras/Raf/MEK/ERK and PI3K/AKT/mTOR pathways [95]. Tan IIA treated MG63 osteosarcoma cells exhibited reduced proliferation and autophagy induction [96]. Administration of Tan IIA to non-obese diabetic-severe combined immunodeficiency (SCID) mice implanted with human osteosarcoma 143B cells led to a significant inhibition of tumor development [42]. Malignant astrocytoma is the most common malignant tumor with strong invasion capability in the central nervous system, where Tan IIA had shown a significant anti-proliferative and pro-apoptotic effect in these cells [97]. In human glioma cell U251, Tan IIA was shown to inhibit the viability of the cells by inducing cells apoptosis and autophagy [37]. Additionally, in cervix carcinoma (CC) stem cells, it has been found that Tan IIA can suppress CC stemnesslike cells migration and invasion [98]. In a study conducted on CC stemness-like cells, pre-treatment with Tan IIA was found to reduce migration that resulted in suppression of HuR protein translocation from the nucleus to the cytoplasm, thereby reducing YAP mRNA stability and transcriptional activity [98]. Tan I treated $\mathrm{H} 28$ and $\mathrm{H} 2452$ mesothelioma cells displayed high cytotoxicity along with autophagic features [39]. Furthermore, the effects of Tan IIA on melanoma A375, MV3, M14, and other human cell lines including HaCat and HUVEC cells were investigated and it has been discovered that Tan IIA inhibited melanoma A375, MV3, and M14 proliferation and reduced CXCL12 levels, in A375 cells, leading to a decrease in invasiveness and migration [41]. Finally, in Tan IIA-treated K562 cells (myelogenous leukaemia), a significant inhibitory effect on the growth, in addition to the activation of apoptosis was observed [99].

\section{In vivo effects of Tanshinones}

The effects of Tan IIA have been evaluated pre-clinically in mouse models of numerous types of cancers. In nude mice bearing BGC823 xenograft (gastric cancer), it has been shown that the combination of chloroquine and Tan I could inhibit tumor growth more efficiently than monotherapy [56]. Tan IIA also suppressed cancerinduced bone pain, or cancer induced bone pain, which is a chronic condition as identified by both ongoing and breakthrough pain. Tan IIA attenuated the expression levels of spinal HMGB1 and levels of inflammatory markers such as IL-1 $\beta$, tumor necrosis factor alpha (TNF- $\alpha$ ), and IL-6 [100]. Moreover, Tan IIA significantly inhibited the neuronal responses of wide dynamic range neurons in spinal deep layers [100]. In Tan IIA treated human osteosarcoma cells 143B, tumor development was significantly inhibited, associated with attenuation of proliferation, migration and invasion, and apoptosis induction [42].

Tan-IIA also increased the sensitivity to irradiation in laryngeal cancer cells both in vitro and in vivo [27]. Tan IIA treatment led to a dramatic 66\% reduction in tumor volume of cervical cancer xenograft athymic nude mice by lowering the expression of proliferation marker; proliferating cell nuclear antigen (PCNA) [19]. In addition, treatment of Tan IIA significantly abrogated the growth in ovarian tumor cells through inducing apoptosis [43]. In vivo, diterpenoid Tan promoted lung PC9 cell apoptosis in a dose-dependent manner, upregulated Bip, IRE1, and TRAF2 protein expressions in tumor tissues, reduced tumor weight and alleviated weight loss [30]. In gastric cancer AGS cells, xenograft SCID mice were treated with Tan IIA for 8 weeks, which significantly decreased the expression levels of epidermal growth factor receptor (EGFR), IGFR, PI3K, AKT, and mTOR proteins in dose-dependent fashion [101]. In BxPC3 (pancreatic cancer) derived xenograft tumor, Tan IIA significantly suppressed the growth of the tumor. Human oral squamous cell carcinoma (OSCC) SCC-9 cells were injected in OSCC xenograft mice models and treated with Tan IIA. The consequent results showed an autophagy-inducing effect against OSCC in a Beclin-1-dependent mechanism of action [90]. In Tan IIA treated APL-bearing mice, a decrease in proliferation and apoptosis induction were observed along with a prolonged survival rate [99]. It has been found that Tan IIA inhibited HIF- $1 \alpha$ and VEGF levels in human breast cancer 
xenografts, resulting in decreased angiogenesis [102]. Recent reports have shown that bone marrow-derived endothelial progenitor cells (EPCs) are potent regulators of angiogenesis, postnatal neovascularization, and metastasis. Tan IIA treatment led to the suppression of VEGF promoted migration and tube formation of human EPCs, without cytotoxic effects. Tan IIA had inhibited VEGF-induced angiogenesis in chick embryo chorioallantoic membrane models. There was also reduced microvessel formation and the expression of EPCspecific markers in mice [103] . Additionally, pre-treatment of ovarian cancer cells with Tan IIA resulted in increased apoptosis [43]. Acetyl Tan IIA derived from the chemical modification of Tan IIA inhibited tumor growth, induced apoptosis, increased water solubility and apoptotic activity on a greater number of cancer cell lines than Tan IIA [18]. ATA was also able to inhibit the growth of HER2 breast cancer positive cells injected in xenograft mice at a faster rate than those pre-treated with Tan IIA. Hence, these in vivo studies have revealed that Tan IIA can act as an effective anti-cancer drug. In addition, the beneficial effects of Tan compounds have been reported clinically on patients with polycystic ovary syndrome, APL and other cancers [104-112].

\section{Effect of Tan on angiogenesis}

Numerous reports have depicted that anti-angiogenic potential of Tan compounds [102, 103]. Tan I can effectively reduce tumor angiogenesis by decreasing phosphorylation of STAT3 at tyrosine 705 residue. Tan I also inhibited angiogenesis in endothelial and tumor cells by reducing hypoxia-induced HIF- $1 \alpha$ accumulation [63]. Moreover, Tan IIA can also attenuate $\beta$-catenin/VEGF-driven angiogenesis by affecting TGF- $\beta 1$ in normoxic and HIF- $1 \alpha$ in hypoxic microenvironments in colorectal cancer [113].

\section{Application of Tan in combination with nanoparticles}

Significant efforts have been made to improve pharmacokinetic parameters of Tanshinones through novel formulations, including using solid lipid nanoparticles (SLN) combined with the Tan active compounds. SLN can protect the pharmaceutical compounds from degrading in various in vivo compartments in which they are released and favour a better control over the drug release profile [14]. In rats, it has been shown that Tan IIA-loaded SLN coated with poloxamer 188 can extend the time of plasma elimination and the mean residence time of Tan IIA [114], reduced opsonisation by serum proteins and macrophage uptake, as well as improved the circulation lifetimes for Tan IIA in plasma [115]. Another combination form that consisted of polylactic acid nanoparticles containing Tan IIA exhibited better performance in displaying pharmaceutical effects [116].

\section{Pharmacokinetic parameters of Tanshinones}

It has been well established that Tanshinones can exhibit remarkable anticancer effects [117-121] but have a limited bioavailability when administered orally [14]. The distribution of four compounds cryptotanshinone, Tan IIA, danshensu, and ferulic acid from an extract was around $60 \%$ in rabbit plasma with a precision of $10 \%$. Previous studies have indicated that the distribution and elimination of cryptotanshinones in rabbits are fast, however, together with danxiongfang, a compound used for the preparation of herbal medicine, it was shown to hinder its distribution being injected through intravenous route from a single dose. Cryptotanshinones at a dose of $100 \mathrm{mg} / \mathrm{kg}$ through oral administration and intraperitoneal routes in rat plasma have shown a bioavailability of $2.05 \%$ and $10.60 \%$, respectively. Numerous research groups have measured diverse pharmacokinetic parameters of Tan compounds in various animal models [122-125] and their findings have aided in understanding the behaviour of these compounds inside the different organisms.

\section{Conclusions}

Compounds extracted from natural agents such as medicinal plant sources possess numerous advantages including low cytotoxicity, capability to affect various oncogenic pathways and novel bioactive structures. They are widely studied due to their therapeutic potential and lower toxicity. A number of studies have suggested that Tanshinones, derived from Salvia miltiorrhiza roots possess remarkable potential as antineoplastic drugs. 
This review analyses the role of various Tanshinones in modulating multiple oncogenic factors that facilitate tumor formation, progression, and metastasis. It has been established that the majority of cancers arise due to a combination of inflammatory events, bacterial infections, dysfunctional cell death mechanisms, and deregulation of cell cycle molecules. Thus, Tanshinones that can target multiple hallmarks are good candidates to prevent/treat tumorigenesis. Interestingly, few reported clinical trials have shown promising results in different cancer patients. Nevertheless, it has been found in several studies that Tanshinones may have a limited bioavailability when administered orally, and thus efforts are being channelized to improve their pharmacokinetic parameters through developing novel formulations. Consequently, in the future, clinical trials will be primarily focused on large, randomized patient groups to better establish the anticancer potential of Tanshinones.

\section{Abbreviations}

APL: acute promyelocytic leukaemia

AR: androgen receptor

$\mathrm{As}_{4} \mathrm{~S}_{4}$ : tetra-arsenic tetra-sulfide

ATRA: all-trans-retinoic acid

Bax: BCL2-associated X protein

Bcl-xL: B-cell lymphoma-extra large

CHOP: CCAAT-enhancer-binding protein homologous protein

CRC: colorectal cancer

DT: Dihydrotanshinone

EGFR: epidermal cell growth factor receptor

EMT: epithelial-mesenchymal transition

EPC: endothelial progenitor cell

EPCs: endothelial progenitor cells

FLIP $_{\text {S }}$ FLICE inhibitory protein

FoxM1: forkhead box M1

HCC: hepatocellular carcinoma

HMGB1: high-mobility group protein B1

HIF1- $\alpha$ : hypoxia-inducible factor 1-alpha

HPV: human papillomavirus

HRE: hypoxia response element

IFGR: insulin-like growth factors

JNK: Jun N-terminal kinase

LDLR: low-density lipoprotein receptor

MAPK: monophosphate-activated protein kinase

MMP: matrix metalloproteinase

OSCC: oral squamous cell carcinoma

PARP: poly ADP-ribose polymerase

PC: prostate cancer

PCNA: proliferating cell nuclear antigen

PI3K: phosphoinositide 3-kinase

p-JNK: p-c-Jun N-terminal kinase

PPAT: phosphoribosyl pyrophosphate amidotransferase 
Prb: retinoblastoma protein

ROS: reactive oxygen species

SCID: severe combined immunodeficiency

SLN: solid lipid nanoparticles

Tan: Tanshinone

Tan I: Tanshinone I

Tan IIA: Tanshinone IIA

VEGF: vascular endothelial growth factor

VEGFR: vascular epidermal growth factor receptor

Bcl-2: B-cell lymphoma-2

IRE1: inositol-requiring protein-1

IGF-1: insulin-like growth factor 1

IGF-1R: insulin-like growth factor type 1 receptor

IL-6: interleukin 6

MMP-2: matrix metalloproteinase 2

MMP-9: matrix metalloproteinase 9

HER2: human epidermal growth factor receptor 2

FOX03a: forkhead box class $03 a$

DR5: death receptor 5

\section{Declarations}

Author contributions

This manuscript is written by IN, SR, MM, and SS. It was edited by MRK, ASN, and KSA. All authors have read and agreed to the published version of the manuscript.

\section{Conflicts of interest}

The authors declare that they have no conflicts of interest.

\section{Ethical approval}

Not applicable.

\section{Consent to participate}

Not applicable.

\section{Consent to publication}

Not applicable.

Availability of data and materials

Not applicable.

\section{Funding}

This work was supported by Higher Education Commission of Pakistan (HEC) grant and National Research Foundation of Korea (NRF) grant funded by the Korean government (MSIP) (NRF-2018R1D1A1B07042969). The funding agencies have no role in the study design; in the collection, analysis and interpretation of the data; in the writing of the report; and in the decision to submit the paper for publication. 


\section{Copyright}

(c) The Author(s) 2020.

\section{References}

1. Plummer M, de Martel C, Vignat J, Ferlay J, Bray F, Franceschi S. Global burden of cancers attributable to infections in 2012: a synthetic analysis. Lancet Glob Health. 2016;4:e609-16.

2. Fangjun L, Zhijia Y. Tumor suppressive roles of eugenol in human lung cancer cells. Thorac Cancer. 2018;9:25-9.

3. Kashyap D, Tuli HS, Yerer MB, Sharma A, Sak K, Srivastava S, et al. Natural product-based nanoformulations for cancer therapy: opportunities and challenges. Semin Cancer Biol. 2019.

4. Bao Y, Kong X, Yang L, Liu R, Shi Z, Li W, et al. Complementary and alternative medicine for cancer pain: an overview of systematic reviews. Evid Based Complement Alternat Med. 2014;2014:170396.

5. Prasannan R, Kalesh KA, Shanmugam MK, Nachiyappan A, Ramachandran L, Nguyen AH, et al. Key cell signaling pathways modulated by zerumbone: role in the prevention and treatment of cancer. Biochem Pharmacol. 2012;84:1268-76.

6. Rajendran P, Li F, Shanmugam MK, Vali S, Abbasi T, Kapoor S, et al. Honokiol inhibits signal transducer and activator of transcription-3 signaling, proliferation, and survival of hepatocellular carcinoma cells via the protein tyrosine phosphatase SHP-1. J Cell Physiol. 2012;227:2184-95.

7. Siveen KS, Ahn KS, Ong TH, Shanmugam MK, Li F, Yap WN, et al. Y-tocotrienol inhibits angiogenesisdependent growth of human hepatocellular carcinoma through abrogation of AKT/mTOR pathway in an orthotopic mouse model. Oncotarget. 2014;5:1897-911.

8. Ramachandran L, Manu KA, Shanmugam MK, Li F, Siveen KS, Vali S, et al. Isorhamnetin inhibits proliferation and invasion and induces apoptosis through the modulation of peroxisome proliferatoractivated receptor $\gamma$ activation pathway in gastric cancer. J Biol Chem. 2012;287:38028-40.

9. Ramchandani S, Naz I, Lee JH, Khan MR, Ahn KS. An overview of the potential antineoplastic effects of casticin. Molecules. 2020;25:1287.

10. Shanmugam MK, Manu KA, Ong TH, Ramachandran L, Surana R, Bist P, et al. Inhibition of CXCR4/CXCL12 signaling axis by ursolic acid leads to suppression of metastasis in transgenic adenocarcinoma of mouse prostate model. Int J Cancer. 2011;129:1552-63.

11. Dai X, Zhang J, Arfuso F, Chinnathambi A, Zayed ME, Alharbi SA, et al. Targeting TNF-related apoptosisinducing ligand (TRAIL) receptor by natural products as a potential therapeutic approach for cancer therapy. Exp Biol Med (Maywood). 2015;240:760-73.

12. Tewari D, Nabavi SF, Nabavi SM, Sureda A, Farooqi AA, Atanasov AG, et al. Targeting activator protein 1 signaling pathway by bioactive natural agents: possible therapeutic strategy for cancer prevention and intervention. Pharmacol Res. 2018;128:366-75.

13. Naz I, Ramchandani S, Khan MR, Yang MH, Ahn KS. Anticancer potential of raddeanin a, a natural triterpenoid isolated from anemone raddeana regel. Molecules. 2020;25:1035.

14. Zhang Y, Jiang P, Ye M, Kim SH, Jiang C, Lü J. Tanshinones: sources, pharmacokinetics and anti-cancer activities. Int J Mol Sci. 2012;13:13621-66.

15. Huang SY, Chang SF, Liao KF, Chiu SC. Tanshinone IIA inhibits epithelial-mesenchymal transition in bladder cancer cells via modulation of STAT3-CCL2 signaling. Int J Mol Sci. 2017;18:1616.

16. Lin H, Zheng L, Li S, Xie B, Cui B, Xia A, et al. Cytotoxicity of Tanshinone IIA combined with Taxol on drugresist breast cancer cells MCF-7 through inhibition of Tau. Phytother Res. 2018;32:667-71.

17. Wang L, Wu J, Lu J, Ma R, Sun D, Tang J. Regulation of the cell cycle and PI3K/Akt/mTOR signaling pathway by tanshinone I in human breast cancer cell lines. Mol Med Rep. 2015;11:931-9. 
18. Tian HL, Yu T, Xu NN, Feng C, Zhou LY, Luo HW, et al. A novel compound modified from tanshinone inhibits tumor growth in vivo via activation of the intrinsic apoptotic pathway. Cancer Lett. 2010;297:18-30.

19. Munagala R, Aqil F, Jeyabalan J, Gupta RC. Tanshinone IIA inhibits viral oncogene expression leading to apoptosis and inhibition of cervical cancer. Cancer Lett. 2015;356:536-46.

20. Chang TW, Lin CY, Tzeng YJ, Lur HS. Synergistic combinations of tanshinone IIA and trans-resveratrol toward cisplatin-comparable cytotoxicity in HepG2 human hepatocellular carcinoma cells. Anticancer Res. 2014;34:5473-80.

21. Wang Y, Song D, Costanza F, Ji G, Fan Z, Cai J, et al. Targeted delivery of tanshinone IIA-conjugated mPEGPLGA-PLL-cRGD nanoparticles to hepatocellular carcinoma. J Biomed Nanotechnol. 2014;10:3244-52.

22. Li H, Wang H, Ma Y, Zhao J. Clarithromycin combined with tanshinone for rhinosinusal and laryngeal radiation injury in patients with nasopharyngeal carcinoma after radiotherapy. Nan Fang Yi Ke Da Xue Xue Bao. 2012;32:1168-70. Chinese.

23. Zhang HS, Zhang FJ, Li H, Liu Y, Du GY, Huang YH. Tanshinone IIA inhibits human esophageal cancer cell growth through miR-122-mediated PKM2 down-regulation. Arch Biochem Biophys. 2016;598:50-6.

24. Zhu YQ, Wang BY, Wu F, An YK, Zhou XQ. Influence of tanshinone IIA on the apoptosis of human esophageal Ec-109 cells. Nat Prod Commun. 2016;11:17-9.

25. Xie J, Liu J, Liu H, Liang S, Lin M, Gu Y, et al. The antitumor effect of tanshinone IIA on anti-proliferation and decreasing VEGF/VEGFR2 expression on the human non-small cell lung cancer A549 cell line. Acta Pharm Sin B. 2015;5:554-63.

26. Xie J, Liu JH, Liu H, Liao XZ, Chen Y, Lin MG, et al. Tanshinone IIA combined with adriamycin inhibited malignant biological behaviors of NSCLC A549 cell line in a synergistic way. BMC Cancer. 2016;16:899.

27. Xu H, Hao YL, Xu LN, Chen L, Xu FW. Tanshinone sensitized the antitumor effects of irradiation on laryngeal cancer via JNK pathway. Cancer Med. 2018;7:5187-93.

28. Wang JF, Feng JG, Han J, Zhang BB, Mao WM. The molecular mechanisms of Tanshinone IIA on the apoptosis and arrest of human esophageal carcinoma cells. Biomed Res Int. 2014;2014:582730.

29. Yan Y, Su W, Zeng S, Qian L, Chen X, Wei J, et al. Effect and mechanism of tanshinone I on the radiosensitivity of lung cancer cells. Mol Pharm. 2018;15:4843-53.

30. Lou ZH, Xia RM, Li XJ, Cheng RB, Shao KD, Zhang GJ. Anti-lung cancer mechanisms of diterpenoid tanshinone via endoplasmic reticulum stress-mediated apoptosis signal pathway. Zhongguo Zhong Yao Za Zhi. 2018;43:4900-7. Chinese.

31. Ma ZL, Zhang BJ, Wang DT, Li X, Wei JL, Zhao BT, et al. Tanshinones suppress AURKA through up-regulation of miR-32 expression in non-small cell lung cancer. Oncotarget. 2015;6:20111-20.

32. Li C, Han X, Zhang H, Wu J, Li B. The interplay between autophagy and apoptosis induced by tanshinone IIA in prostate cancer cells. Tumour Biol. 2016;37:7667-74.

33. Ketola K, Viitala M, Kohonen P, Fey V, Culig Z, Kallioniemi O, et al. High-throughput cell-based compound screen identifies pinosylvin methyl ether and tanshinone IIA as inhibitors of castration-resistant prostate cancer. J Mol Biochem. 2016;5:12-22.

34. Liu W, Zhou J, Geng G, Shi Q Sauriol F, Wu JH. Antiandrogenic, maspin induction, and antiprostate cancer activities of tanshinone IIA and its novel derivatives with modification in ring A. J Med Chem. 2012;55:971-5.

35. Xu D, Lin TH, Zhang C, Tsai YC, Li S, Zhang J, et al. The selective inhibitory effect of a synthetic tanshinone derivative on prostate cancer cells. Prostate. 2012;72:803-16.

36. Wang H, Su X, Fang J, Xin X, Zhao X, Gaur U, et al. Tanshinone IIA attenuates insulin like growth factor 1 -induced cell proliferation in PC12 cells through the PI3K/Akt and MEK/ERK pathways. Int J Mol Sci. 2018;19:2719. 
37. Ding L, Wang S, Wang W, Lv P, Zhao D, Chen F, et al. Tanshinone IIA affects autophagy and apoptosis of glioma cells by inhibiting phosphatidylinositol 3-Kinase/Akt/Mammalian target of rapamycin signaling pathway. Pharmacology. 2017;99:188-95.

38. Li Q Zhang J, Liang Y, Mu W, Hou X, Ma X, et al. Tanshinone l exhibits anticancer effects in human endometrial carcinoma HEC-1-A cells via mitochondrial mediated apoptosis, cell cycle arrest and inhibition of JAK/STAT signalling pathway. J BUON. 2018;23:1092-6.

39. Lee J, Sohn EJ, Yoon S, Won G, Kim CG, Jung JH, et al. Activation of JNK and IRE1 is critically involved in tanshinone I-induced p62 dependent autophagy in malignant pleural mesothelioma cells: implication of p62 UBA domain. Oncotarget. 2017;8:25032-45.

40. Zhen X, Cen J, Li YM, Yan F, Guan T, Tang XZ. Cytotoxic effect and apoptotic mechanism of tanshinone A, a novel tanshinone derivative, on human erythroleukemic K562 cells. Eur J Pharmacol. 2011;667:129-35.

41. Li X, Li Z, Li X, Liu B, Liu Z. Mechanisms of Tanshinone II a inhibits malignant melanoma development through blocking autophagy signal transduction in A375 cell. BMC Cancer. 2017;17:357.

42. Huang ST, Huang CC, Huang WL, Lin TK, Liao PL, Wang PW, et al. Tanshinone IIA induces intrinsic apoptosis in osteosarcoma cells both in vivo and in vitro associated with mitochondrial dysfunction. Sci Rep. 2017;7:40382.

43. Zhang X, Zhou Y, Gu YE. Tanshinone IIA induces apoptosis of ovarian cancer cells in vitro and in vivo through attenuation of PI3K/AKT/JNK signaling pathways. Oncol Lett. 2019;17:1896-902.

44. Chang CC, Kuan CP, Lin JY, Lai JS, Ho TF. Tanshinone IIA facilitates TRAIL sensitization by up-regulating DR5 through the ROS-JNK-CHOP signaling axis in human ovarian carcinoma cell lines. Chem Res Toxicol. 2015;28:1574-83.

45. Li N, Yang L, Zhang B, Chen S. Tanshinone IIA effects on ovarian cancer cell line. J Pharm Pharmacol. 2018;70:1369-77.

46. Zhang J, Ahn KS, Kim C, Shanmugam MK, Siveen KS, Arfuso F, et al. Nimbolide-induced oxidative stress abrogates STAT3 signaling cascade and inhibits tumor growth in transgenic adenocarcinoma of mouse prostate model. Antioxid Redox Signal. 2016;24:575-89.

47. Li F, Shanmugam MK, Chen L, Chatterjee S, Basha J, Kumar AP, et al. Garcinol, a polyisoprenylated benzophenone modulates multiple proinflammatory signaling cascades leading to the suppression of growth and survival of head and neck carcinoma. Cancer Prev Res (Phila). 2013;6:843-54.

48. Kim C, Lee SG, Yang WM, Arfuso F, Um JY, Kumar AP, et al. Formononetin-induced oxidative stress abrogates the activation of STAT3/5 signaling axis and suppresses the tumor growth in multiple myeloma preclinical model. Cancer Lett. 2018;431:123-41.

49. Ashrafizadeh M, Javanmardi S, Moradi-Ozarlou M, Mohammadinejad R, Farkhondeh T, Samarghandian $\mathrm{S}$, et al. Natural products and phytochemical nanoformulations targeting mitochondria in oncotherapy: an updated review on resveratrol. Biosci Rep. 2020;40:BSR20200257.

50. Hemmings BA, Restuccia DF. PI3K-PKB/Akt pathway. Cold Spring Harb Perspect Biol. 2012;4:a011189.

51. Ong PS, Wang LZ, Dai X, Tseng SH, Loo SJ, Sethi G. Judicious toggling of mTOR activity to combat insulin resistance and cancer: current evidence and perspectives. Front Pharmacol. 2016;7:395.

52. He L, Gu K. Tanshinone IIA regulates colorectal cancer apoptosis via attenuation of Parkin-mediated mitophagy by suppressing AMPK/Skp2 pathways. Mol Med Rep. 2018;18:1692-703.

53. Lin CY, Chang TW, Hsieh WH, Hung MC, Lin IH, Lai SC, et al. Simultaneous induction of apoptosis and necroptosis by Tanshinone IIA in human hepatocellular carcinoma HepG2 cells. Cell Death Discov. 2016;2:16065.

54. Zhang Y, Guo S, Fang J, Peng B, Zhang Y, Cao T. Tanshinone IIA inhibits cell proliferation and tumor growth by downregulating STAT3 in human gastric cancer. Exp Ther Med. 2018;16:2931-7.

55. Bai Y, Zhang L, Fang X, Yang Y. Tanshinone IIA enhances chemosensitivity of colon cancer cells by suppressing nuclear factor-кB. Exp Ther Med. 2016;11:1085-9. 
56. Jing X, Xu Y, Cheng W, Guo S, Zou Y, He L. Tanshinone I induces apoptosis and pro-survival autophagy in gastric cancers. Cancer Chemother Pharmacol. 2016;77:1171-81.

57. Lu M, Wang C, Wang J. Tanshinone I induces human colorectal cancer cell apoptosis: the potential roles of Aurora A-p53 and survivin-mediated signaling pathways. Int J Oncol. 2016;49:603-10.

58. Su CC. Tanshinone IIA inhibits gastric carcinoma AGS cells by decreasing the protein expression of VEGFR and blocking Ras/Raf/MEK/ERK pathway. Int J Mol Med. 2018;41:2389-96.

59. Wang C, Kar S, Lai X, Cai W, Arfuso F, Sethi G, et al. Triple negative breast cancer in Asia: an insider's view. Cancer Treat Rev. 2018;62:29-38.

60. Shanmugam MK, Ahn KS, Hsu A, Woo CC, Yuan Y, Tan KHB, et al. Thymoquinone inhibits bone metastasis of breast cancer cells through abrogation of the CXCR4 signaling axis. Front Pharmacol. 2018;9:1294.

61. Jia LY, Shanmugam MK, Sethi G, Bishayee A. Potential role of targeted therapies in the treatment of triplenegative breast cancer. Anticancer Drugs. 2016;27:147-55.

62. Shin EM, Hay HS, Lee MH, Goh JN, Tan TZ, Sen YP, et al. DEAD-box helicase DP103 defines metastatic potential of human breast cancers. J Clin Invest. 2014;124:3807-24.

63. Wang Y, Li JX, Wang YQ, Miao ZH. Tanshinone I inhibits tumor angiogenesis by reducing Stat3 phosphorylation at Tyr705 and hypoxia-induced HIF-1 $\alpha$ accumulation in both endothelial and tumor cells. Oncotarget. 2015;6:16031-42.

64. Ferlay J, Soerjomataram I, Dikshit R, Eser S, Mathers C, Rebelo M, et al. Cancer incidence and mortality worldwide: sources, methods and major patterns in GLOBOCAN 2012. Int J Cancer. 2015;136:E359-86.

65. Ningegowda R, Shivananju NS, Rajendran P, Basappa, Rangappa KS, Chinnathambi A, et al. A novel 4,6-disubstituted-1,2,4-triazolo-1,3,4-thiadiazole derivative inhibits tumor cell invasion and potentiates the apoptotic effect of TNF $\alpha$ by abrogating NF-KB activation cascade. Apoptosis. 2017;22:145-57.

66. Manu KA, Shanmugam MK, Ramachandran L, Li F, Siveen KS, Chinnathambi A, et al. Isorhamnetin augments the anti-tumor effect of capecitabine through the negative regulation of NF- $\mathrm{KB}$ signaling cascade in gastric cancer. Cancer Lett. 2015;363:28-36.

67. Kim MK, Park GH, Eo HJ, Song HM, Lee JW, Kwon MJ, et al. Tanshinone I induces cyclin D1 proteasomal degradation in an ERK1/2 dependent way in human colorectal cancer cells. Fitoterapia. 2015;101:162-8.

68. Kim DH, Shin EA, Kim B, Shim BS, Kim SH. Reactive oxygen species-mediated phosphorylation of p38 signaling is critically involved in apoptotic effect of Tanshinone I in colon cancer cells. Phytother Res. 2018;32:1975-82.

69. Yu J, Wang X, Li Y, Tang B. Tanshinone IIA suppresses gastric cancer cell proliferation and migration by downregulation of FOXM1. Oncol Rep. 2017;37:1394-400.

70. Cheng R, Chen J, Wang Y, Ge Y, Huang Z, Zhang G. Dihydrotanshinone induces apoptosis of SGC7901 and MGC803 cells via activation of JNK and p38 signalling pathways. Pharm Biol. 2016;54:3019-25.

71. Ma S, Lei Y, Zhang L, Wang J. Research on the inhibiting effect of Tanshinone IIA on colon cancer cell growth via COX-2-Wnt/ $\beta$-catenin signaling pathway. J BUON. 2018;23:1337-42.

72. Qian J, Fang D, Lu H, Cao Y, Zhang J, Ding R, et al. Tanshinone IIA promotes IL2-mediated SW480 colorectal cancer cell apoptosis by triggering INF2-related mitochondrial fission and activating the Mst1-Hippo pathway. Biomed Pharmacother. 2018;108:1658-69.

73. Jieensinue S, Zhu H, Li G, Dong K, Liang M, Li Y. Tanshinone IIA reduces SW837 colorectal cancer cell viability via the promotion of mitochondrial fission by activating JNK-Mff signaling pathways. BMC Cell Biol. 2018;19:21.

74. Palumbo A, Jr, Meireles Da Costa N, Pontes B, Leite de Oliveira F, Lohan Codeço M, Ribeiro Pinto LF, et al. Esophageal cancer development: crucial clues arising from the extracellular matrix. Cells. 2020;9:455.

75. Siegel RL, Miller KD, Jemal A. Cancer statistics, 2020. CA Cancer J Clin. 2020;70:7-30. 
76. Mastron JK, Siveen KS, Sethi G, Bishayee A. Silymarin and hepatocellular carcinoma: a systematic, comprehensive, and critical review. Anticancer Drugs. 2015;26:475-86.

77. Swamy SG, Kameshwar VH, Shubha PB, Looi CY, Shanmugam MK, Arfuso F, et al. Targeting multiple oncogenic pathways for the treatment of hepatocellular carcinoma. Target Oncol. 2017;12:1-10.

78. Mohan CD, Bharathkumar H, Bulusu KC, Pandey V, Rangappa S, Fuchs JE, et al. Development of a novel azaspirane that targets the Janus kinase-signal transducer and activator of transcription (STAT) pathway in hepatocellular carcinoma in vitro and in vivo. J Biol Chem. 2014;289:34296-307.

79. Tan SM, Li F, Rajendran P, Kumar AP, Hui KM, Sethi G. Identification of beta-escin as a novel inhibitor of signal transducer and activator of transcription 3/Janus-activated kinase 2 signaling pathway that suppresses proliferation and induces apoptosis in human hepatocellular carcinoma cells. J Pharmacol Exp Ther. 2010;334:285-93.

80. Chen HC, Chen PY, Wu MJ, Tai MH, Yen JH. Tanshinone IIA modulates low density lipoprotein uptake via down-regulation of PCSK9 gene expression in HepG2 cells. PLoS One. 2016;11:e0162414.

81. Ren X, Wang C,Xie B, Hu L, Chai H, Ding L, etal. Tanshinone IIA induced cell death via miR30b-p53-PTPN11/ SHP2 signaling pathway in human hepatocellular carcinoma cells. Eur J Pharmacol. 2017;796:233-41.

82. Cheng MA, Chou FJ, Wang K, Yang R, Ding J, Zhang Q et al. Androgen receptor (AR) degradation enhancer ASC-J9(®) in an FDA-approved formulated solution suppresses castration resistant prostate cancer cell growth. Cancer Lett. 2018;417:182-91.

83. Hung YS, Chen JS, Chen YY, Lu CH, Chang PH, Chou WC. Incidence, risk factors, and outcomes of arterial thromboembolism in patients with pancreatic cancer following palliative chemotherapy. Cancers (Basel). 2018;10:432.

84. Jung YY, Shanmugam MK, Narula AS, Kim C, Lee JH, Namjoshi OA, et al. Oxymatrine attenuates tumor growth and deactivates STAT5 signaling in a lung cancer xenograft model. Cancers (Basel). 2019;11:49.

85. Lee JH, Chinnathambi A, Alharbi SA, Shair OHM, Sethi G, Ahn KS. Farnesol abrogates epithelial to mesenchymal transition process through regulating Akt/mTOR pathway. Pharmacol Res. 2019;150:104504.

86. Baek SH, Ko JH, Lee JH, Kim C, Lee H, Nam D, et al. Ginkgolic acid inhibits invasion and migration and TGF- $\beta$ induced EMT of lung cancer cells through PI3K/Akt/mTOR inactivation. J Cell Physiol. 2017;232:346-54.

87. Sinha N, Panda PK, Naik PP, Das DN, Mukhopadhyay S, Maiti TK, et al. Abrus agglutinin promotes irreparable DNA damage by triggering ROS generation followed by ATM-p73 mediated apoptosis in oral squamous cell carcinoma. Mol Carcinog. 2017;56:2400-13.

88. Sawhney M, Rohatgi N, Kaur J, Shishodia S, Sethi G, Gupta SD, et al. Expression of NF-kappaB parallels COX-2 expression in oral precancer and cancer: association with smokeless tobacco. Int J Cancer. 2007;120:2545-56.

89. Ding L, Wang S, Qu X, Wang J. Tanshinone IIA sensitizes oral squamous cell carcinoma to radiation due to an enhanced autophagy. Environ Toxicol Pharmacol. 2016;46:264-9.

90. Qiu Y, Li C, Wang Q, Zeng X, Ji P. Tanshinone IIA induces cell death via Beclin-1-dependent autophagy in oral squamous cell carcinoma SCC-9 cell line. Cancer Med. 2018;7:397-407.

91. Lin CJ, Lo UG, Hsieh JT. The regulatory pathways leading to stem-like cells underlie prostate cancer progression. Asian J Androl. 2019;21:233-40.

92. Shanmugam MK, Ong TH, Kumar AP, Lun CK, Ho PC, Wong PT, et al. Ursolic acid inhibits the initiation, progression of prostate cancer and prolongs the survival of TRAMP mice by modulating pro-inflammatory pathways. PLoS One. 2012;7:e32476.

93. Lee JH, Kim C, Baek SH, Ko JH, Lee SG, Yang WM, et al. Capsazepine inhibits JAK/STAT3 signaling, tumor growth, and cell survival in prostate cancer. Oncotarget. 2017;8:17700-11.

94. Sikka S, Chen L, Sethi G, Kumar AP. Targeting PPAR $\gamma$ signaling cascade for the prevention and treatment of prostate cancer. PPAR Res. 2012;2012:968040. 
95. Su CC. Tanshinone IIA can inhibit MiaPaCa-2 human pancreatic cancer cells by dual blockade of the Ras/ Raf/MEK/ERK and PI3K/AKT/mTOR pathways. Oncol Rep. 2018;40:3102-11.

96. Ma K, Zhang C, Huang MY, Guo YX, Hu GQ. Crosstalk between Beclin-1-dependent autophagy and caspase-dependent apoptosis induced by tanshinone IIA in human osteosarcoma MG-63 cells. Oncol Rep. 2016;36:1807-18.

97. Dong W, Zhang Y, Chen X, Jia Y. High-dose tanshinone IIA suppresses migration and proliferation while promoting apoptosis of astrocytoma cells via Notch-1 pathway. Neurochem Res. 2018;43:1855-61.

98. Qin J, Shi H, Xu Y, Zhao F, Wang Q. Tanshinone IIA inhibits cervix carcinoma stem cells migration and invasion via inhibiting YAP transcriptional activity. Biomed Pharmacother. 2018;105:758-65.

99. Zhang $\mathrm{K}$, Li J, Meng W, Xing H, Yang Y. Tanshinone IIA inhibits acute promyelocytic leukemia cell proliferation and induces their apoptosis in vivo. Blood Cells Mol Dis. 2016;56:46-52.

100. Hao W, Chen L, Wu LF, Yang F, Niu JX, Kaye AD, et al. Tanshinone IIA exerts an antinociceptive effect in rats with cancer-induced bone pain. Pain Physician. 2016;19:465-76.

101. Su CC, Chiu TL. Tanshinone IIA decreases the protein expression of EGFR, and IGFR blocking the PI3K/ Akt/mTOR pathway in gastric carcinoma AGS cells both in vitro and in vivo. Oncol Rep. 2016;36:1173-9.

102. Li G, Shan C, Liu L, Zhou T, Zhou J, Hu X, et al. Tanshinone IIA inhibits HIF-1 $\alpha$ and VEGF expression in breast cancer cells via mTOR/p70S6K/RPS6/4E-BP1 signaling pathway. PLoS One. 2015;10:e0117440.

103. Lee HP, Liu YC, Chen PC, Tai HC, Li TM, Fong YC, et al. Tanshinone IIA inhibits angiogenesis in human endothelial progenitor cells in vitro and in vivo. Oncotarget. 2017;8:109217-27.

104. Shen W, Zhang Y, Li W, Cong J, Zhou Y, Ng EH, et al. Effects of tanshinone on hyperandrogenism and the quality of life in women with polycystic ovary syndrome: protocol of a double-blind, placebo-controlled, randomised trial. BMJ Open. 2013;3:e003646.

105. Madan V, Shyamsunder P, Han L, Mayakonda A, Nagata Y, Sundaresan J, et al. Comprehensive mutational analysis of primary and relapse acute promyelocytic leukemia. Leukemia. 2016;30:1672-81.

106. Garg M, Nagata Y, Kanojia D, Mayakonda A, Yoshida K, Haridas Keloth S, et al. Profiling of somatic mutations in acute myeloid leukemia with FLT3-ITD at diagnosis and relapse. Blood. 2015;126:2491-501.

107. Yang L, Gong YP, Yang YM, Luo S. A successful case of tanshinone II A treatment for relapsed acute promyelocytic leukemia after maintainance therapy of all-trans retinoic acid and arsenic trioxide. Sichuan Da Xue Xue Bao Yi Xue Ban. 2010;41:1065-7. Chinese.

108. Yang YM, Liu T. Complete remission of acute promyelocytic leukemia resisting all-trans retinoic acid of one case treated by tanshinone II A. Sichuan Da Xue Xue Bao Yi Xue Ban. 2006;37:965-7. Chinese.

109. Ji B, Wang S, Jing B. Study of composite Salviae miltiorrhizae injection on acute leukemia. Mod J Integr Tradit Chin West Med. 2004;22. Chinese.

110. Xiang Y, Huang SL, Guo AX, Wei AH, Zhang L, Sun SJ. The influence on long-term survey of the patients with acute promyelocytic leukemia treated with compound huangdai tablets and chemotherapy. Chin J Clin Hematol. 2003;16:204-6.

111. Wallace S, Carrasco CH, Charnsangavej C, Richli WR, Wright K, Gianturco C. Hepatic artery infusion and chemoembolization in the management of liver metastases. Cardiovasc Intervent Radiol. 1990;13:153-60.

112. Chen X, Liang $Q$, Li X, Zhang Y, Li J, Liang Z, et al. Effect of composite salviae dropping pill combined with chemotherapy in 41 cases with pancreatic carcinoma. J Oncol. 2005;13:19-51.

113. Sui H, Zhao J, Zhou L, Wen H, Deng W, Li C, et al. Tanshinone IIA inhibits $\beta$-catenin/VEGF-mediated angiogenesis by targeting TGF- $\beta 1$ in normoxic and HIF- $1 \alpha$ in hypoxic microenvironments in human colorectal cancer. Cancer Lett. 2017;403:86-97.

114. Liu J, Zhu J, Du Z, Qin B. Preparation and pharmacokinetic evaluation of Tashinone IIA solid lipid nanoparticles. Drug Dev Ind Pharm. 2005;31:551-6. 
115. Zhang WL, Liu JP, Liu XX, Chen ZQ. Stealth tanshinone IIA-loaded solid lipid nanoparticles: effects of poloxamer 188 coating on in vitro phagocytosis and in vivo pharmacokinetics in rats. Yao Xue Xue Bao. 2009;44:1421-8.

116. Li Q Wang Y, Feng N, Fan Z, Sun J, Nan Y. Novel polymeric nanoparticles containing tanshinone IIA for the treatment of hepatoma. J Drug Target. 2008;16:725-32.

117. Jeon YJ, Kim JS, Hwang GH, Wu Z, Han HJ, Park SH, etal. Inhibition of cytochrome P450 2J2 by tanshinone IIA induces apoptotic cell death in hepatocellular carcinoma HepG2 cells. Eur J Pharmacol. 2015;764:480-8.

118. Zhang RW, Liu ZG, Xie Y, Wang LX, Li MC, Sun X. In vitro inhibition of invasion and metastasis in colon cancer cells by TanIIA. Genet Mol Res. 2016;15.

119. Su CC. Tanshinone IIA decreases the migratory ability of AGS cells by decreasing the protein expression of matrix metalloproteinases, nuclear factor KB-p65 and cyclooxygenase-2. Mol Med Rep. 2016;13:1263-8.

120. Won SH, Lee HJ, Jeong SJ, Lü J, Kim SH. Activation of p53 signaling and inhibition of androgen receptor mediate tanshinone IIA induced G1 arrest in LNCaP prostate cancer cells. Phytother Res. 2012;26:669-74.

121. Zhang Y, Won SH, Jiang C, Lee HJ, Jeong SJ, Lee EO, et al. Tanshinones from Chinese medicinal herb Danshen (Salvia miltiorrhiza Bunge) suppress prostate cancer growth and androgen receptor signaling. Pharm Res. 2012;29:1595-608.

122. LiX, LiX, Wang L, LiY,XuY,Xue M. Simultaneous determination of danshensu, ferulicacid, cryptotanshinone and tanshinone IIA in rabbit plasma by HPLC and their pharmacokinetic application in danxiongfang. J Pharm Biomed Anal. 2007;44:1106-12.

123. Li XL, Li XR, Wang LJ, Li YH, Xu YX, Xue M. Pharmacokinetics of cryptotanshinone used alone or combined with danxiongfang in rabbits. Chinese Pharmacological Bulletin. 2007;23:1102-5.

124. Guo ZJ, Zhang Y, Tang X, Li H, Sun QS. Pharmacokinetic interaction between tanshinones and polyphenolic extracts of salvia miltinorrhiza BUNGE after intravenous administration in rats. Biol Pharm Bull. 2008;31:1469-74.

125. Zhang J, Huang M, Guan S, Bi HC, Pan Y, Duan W, et al. A mechanistic study of the intestinal absorption of cryptotanshinone, the major active constituent of Salvia miltiorrhiza. J Pharmacol Exp Ther. 2006;317:1285-94. 